\title{
Escolásticos españoles y subjetivismo moderno (un comentario sobre el concepto de derecho en Luis de Molina y Francisco Suárez)
}

\author{
Manuel J. RODRÍGUEZ PUERTO \\ Universidad de Cádiz \\ (mjesus.rodriguez@uca.es)
}

\begin{abstract}
RESUMEN
El derecho como libertad individual es una característica central del pensamiento moderno. El desarrollo de este subjetivismo jurídico está vinculado a la Escuela de Derecho Natural Moderno, pero tiene precedentes en la Teología escolástica, especialmente en España. El presente artículo pretende discutir el papel representado por algunos escolásticos españoles en el origen del individualismo jurídico moderno
\end{abstract}

PALABRAS CLAVE: derecho; libertad; facultad; Escolástica

\begin{abstract}
The right as individual liberty is a central feature of the modern thought. The development of this legal subjectivism is bound to the Modern Natural Law School, but has precedents in the Scholastic Theology, especially in Spain. The present paper intends to dicuss the role played by some Spanish Scholastic in the origin of modern legal individualism
\end{abstract}

KEY WORDS: right; liberty; faculty; Scholastic

\section{Planteamiento de la cuestión}

Una de las manifestaciones más claras del concepto moderno de subjetividad ha sido la identificación del derecho con una esfera de libertad emanada del mismo individuo. Quizá la elaboración teórica más sofisticada de esa noción de derecho proceda de la Escuela de Derecho Natural Moderno. Su núcleo doctrinal era la concepción del ser humano como individuo dotado de libertad natural que pacta para construir un poder político protector de esa libertad. El derecho natural no era para esta Escuela un ordenamiento de normas inmutables y modélicas para el derecho humano positivo, sino un conjunto de exigencias éticas centradas en la libertad ${ }^{1}$.

\footnotetext{
${ }^{1}$ Sobre las características de esa corriente vid. los estudios de F. CARPINTERO, "La independencia y autonomía del individuo: Los orígenes de la <<persona jurídica>>", Anuario de Filosofía del Derecho, 4 (1987); "Voluntarismo y contractualismo: una visión sucinta de la Escuela de Derecho Natural Moderno", Persona y Derecho, 13 (1985); Una introducción a la ciencia jurídica, Madrid, Civitas, 1988, 20 y ss. El mayor grado de sofisticación la alcanzó esta Escuela con Immanuel Kant y sus discípulos; pero la doctrina jurídica que mantuvieron los kantianos no era solo una derivación jurídica de la epistemología del maestro, sino una reelaboración final de las ideas que la Escuela de Derecho natural moderno había desarrollado desde el siglo XVII. Vid. F. CARPINTERO, La cabeza de Jano, Cádiz, Servicio de Publicaciones de la
} 
Cuando estos iusnaturalistas modernos comenzaron a preocuparse de historiar los comienzos de su disciplina (a principios del siglo XVIII), situaron el origen en la obra de Hugo Grocio (1583-1645) y desdeñaron las aportaciones de los autores anteriores (teólogos y juristas) como logomaquias escolásticas. Ese desprecio estaba motivado por las peculiaridades de la guerra de religión trasladada ahora al ámbito intelectual. Los iusnaturalistas modernos fueron protestantes y no podían aceptar precedentes en el campo católico; por eso eligieron al primer protestante que había escrito una obra relevante para las teorías modernas: el arminiano Hugo Grocio ${ }^{2}$.

Sin embargo, los precedentes de esa Modernidad individualista estaban ahí, y procedían en buena parte de juristas y teólogos escolásticos españoles. Desde hace bastante tiempo la historiografía de ha encargado de redescubrirlos ${ }^{3}$. El propósito de estas páginas es más modesto: sólo indicar algunos aspectos del concepto de derecho elaborado por integrantes de la Segunda Escolástica Española desde el punto de vista de su carácter incipientemente moderno. Por cuestiones de espacio, pero también de importancia, me centraré en Luis de Molina y Francisco Suárez.

\section{El concepto de facultad jurídica}

A la hora de explicar el nacimiento de la idea de un derecho subjetivo centrado en la libertad individual es necesario diferenciar dos elementos imprescindibles para su configuración. En primer lugar es preciso desarrollar un concepto entendido al modo de una facultad o poder para actuar. En segundo lugar, esa facultad deberá derivarse directamente desde la misma individualidad, sin necesidad de instancias objetivas ajenas al individuo que configuren o autoricen el derecho. La unión de ambos elementos la llevó a cabo la ya mencionada Escuela de Derecho Natural Moderno desde la segunda mitad del siglo XVII hasta fines del XVIII. Pero no fue una tarea sencilla, porque la mentalidad dominante entre los juristas, influida por el derecho romano, no iba por esa vía. Desde fines del siglo XI, la redescubierta Compilación de Justiniano fue estudiada

Universidad de Cádiz, 1989, per totum.

2 Sobre este conflicto vid. F. CARPINTERO, "La modernidad jurídica y los católicos", Anuario de Filosofía del Derecho, 5 (1988), 383-410. Por supuesto, Grocio no fue el primer protestante que se ocupó de estas cuestiones, ni el que plasmó contenidos más enjundiosos sobre el derecho; pero sí el que logró redactar un tratado relativamente sistematizado y conciso que además aunaba las nuevas inquietudes de la época.

3 Vid. por ejemplo, la aportación que supuso el libro de OTTO v. GIERKE, Johannes Althusius und die Entwicklung der naturrechtlichen Staatstheorien. Zugleich ein Beitrag zur Geschichte der Rechtssystematik, reprint, Aaalen, Scientia, 1981, 97 y ss., 156-157. 
infatigablemente y se convirtió en el modelo europeo de ciencia jurídica. Sin embargo, los romanos no habían desarrollado una noción teórica del derecho (ius) a partir de la facultad o poder personal y los romanistas medievales tampoco la adoptaron, al menos en principio ${ }^{4}$. Para los romanistas lo jurídico era inducido desde la red de interrelaciones y las necesidades y causas que daban sentido a esas interrelaciones; la equidad discernible en esas situaciones debía inspirar las normas que a su vez utilizaban los juristas para declarar el derecho entendido como solución justa. El derecho no estaba en el poder de actuación de los sujetos que intervenían en un asunto, sino en la solución ajustada a las exigencias del problema y a las razones que fundaban la ley. En el siglo XIII un teólogo como Tomás de Aquino precisó esa mentalidad al explicar que el derecho (ius) era el objeto de la justicia, es decir la deuda conducta debida dentro de una relación de justicia, caracterizada por la alteridad; el criterio para conocer el comportamiento justo dependía del sentido o finalidad de la interrelación (una compraventa, un arrendamiento, etc.), es decir, de la “cosa” que unía a los intervinientes. Por eso Tomás sostiene que el derecho es un medium rei; la expresión indica que el medio u objeto de la virtud de la justicia no reside en los aspectos personales, sino reales que unen a las personas y constituyen la deuda o comportamiento justo ${ }^{5}$. Con el paso del tiempo, el ius commune sí vio la aparición de la acepción de derecho como facultad, aunque nunca desempeñara el papel central ${ }^{6}$.

Sin embargo, los romanistas introdujeron una cuña de ambigüedad. Al tratar el problema del derecho natural, comentaron las diversas acepciones contenidas en la Compilación justinianea; entre ellas estaba la igual libertad propia del estado de naturaleza: esta primera etapa de la humanidad se había caracterizado por la inexistencia de leyes, gobiernos, propiedades, de cualquier institución que pudiera limitar la libertad (salvo principios morales básicos). Sin embargo, esta libertad no desempeñaba el papel de

\footnotetext{
${ }^{4}$ La iurisprudentia clásica no concibió la noción de ius como poder personal, sino como juicio justo sobre un asunto; desde luego, las conductas enjuiciadas podían ser facultades y poderes, pero estos no eran "derechos" en sentido subjetivo. En la época postclásica sí aparecen las primeras manifestaciones de un ius normativo desde el que emanan derechos para hacer ciertas cosas. Vid. el estado de la cuestión en J.J. MEGÍAS, "El subjetivismo jurídico y el derecho subjetivo en los textos romanos", en VV.AA., El derecho subjetivo en su historia, Cádiz, Servicio de Publicaciones de la Universidad de Cádiz, 2003, per totum.

${ }^{5}$ Los textos claves para esta explicación son TOMÁS DE AQUINO, Summa Theologiae, II-II, q. 57 y q. 58 (especialmente el artículo. 10). La edición manejada es la disponible digitalmente gracias a E. Alarcón en http://www.corpusthomisticum.org, consultada el 15-05-2011.

${ }^{6}$ Sólo en el siglo XVI, bajo la influencia del Humanismo jurídico y las críticas a todo el sistema del derecho común, algunos juristas conceden a esta idea una posición más destacada, aunque la mayoría siguiera defendiendo las concepciones que podemos considerar tradicionales. Vid. mi estudio "Jus Commune y derechos subjetivos en el siglo XVI", en El derecho subjetivo en su historia, cit.
} 
modelo del derecho de cada sociedad política; estos juristas entendían que, en razón de utilidades sobrevenidas, la libertad natural podía ser limitada justamente; tanto el derecho de gentes como el civil (en sentido romano) desempeñaban esa función. Dicho de otro modo: las regulaciones jurídicas concretas no tenían por qué emanar de la libertad individual ${ }^{7}$. No obstante, en el trasfondo de la mentalidad jurídica medieval permaneció la idea de que, por naturaleza, todos los seres humanos son libres, como contrapunto al ius derivado del entramado social.

La actitud ante la posibilidad de concebir facultades jurídicas era parcialmente diferente en el derecho canónico. En efecto, ya desde el siglo XII, es perceptible el empleo de la palabra ius para nombrar una facultad o poder para actuar jurídicamente . $^{8}$ Pero tampoco encontramos en estos juristas una teorización del empleo de esta acepción. Al fin y al cabo los juristas tanto romanistas como canonistas no eran especialmente aficionados a la especulación; su preocupación conceptual estaba centrada casi siempre en aquello que les resultara útil para resolver problemas concretos.

En realidad esa tarea estuvo a cargo de los teólogos que llamamos escolásticos, en el seno de un debate con miras más extensas que las cuestiones específicamente jurídicas. En efecto, a partir del siglo XIV estaba en juego la noción misma de normatividad práctica. La mentalidad romanista, apoyada por Tomás de Aquino, afirmaba la normatividad de lo cotidiano; a partir de las exigencias lanzadas por la vida social, y asistidos por los primeros principios de la ley natural, el jurista era capaz de conocer lo justo. En cambio, otra línea de pensamiento iniciada por Duns Scoto y que en líneas generales podemos considerar más afín a la teología desarrollada por los franciscanos (aunque no todos pertenecieran a la orden) remitió el origen último de la obligatoriedad práctica a la voluntad divina. Desde este punto de vista, el derecho fue concebido como un poder unido al ser humano y otorgado por el mandato divino, originariamente, o por el gobernante humano. Las obras de Juan de Gerson (1363-1429) o de Conrado de Summenhart (1450/1460-1502) reflejaron esas concepciones y fueron enormemente

\footnotetext{
${ }^{7}$ Sobre el ius naturale en el derecho común medieval, vid. F. CARPINTERO, "Sobre la génesis del derecho natural racionalista en los juristas de los siglos XIV-XVII", Anuario de Filosofia del Derecho, 18, (1975); "El derecho natural laico en la Edad Media", Persona y Derecho, 8 (1981). Ambos per totum. F. CARPINTERO, Historia breve del Derecho Natural. Madrid, Colex, 2000, 13 y ss.

8 Sobre el papel desempeñado por los canonistas cfr. B. TIERNEY, The Idea of Natural Rights. Studies on Natural Rights, Natural Law and Church Law. 1150-1625. Athena (Georgia), Scholar Press, 1997, 36 y ss.
} 
influyentes 9 .

Esa situación académica es la que encuentran los escolásticos españoles a principios del siglo XVI, aunque esa época también vive un momento de relanzamiento del tomismo (pensemos en la obra de Tomás de Vío o de Konrad Koellin). De manera coherente, Francisco de Vitoria (1483/1486-1546) expone el concepto de derecho tomista como cosa justa objeto de la justicia, pero desliza matices que no son tomistas: considera que la ley es también acepción del derecho y a la hora de estudiar la propiedad (dominium) lo llama ius: la influencia de la Escolástica bajomedieval era inevitable a esas alturas ${ }^{10}$. Es una actitud similar a la de su compañero de orden, Domingo de Soto (1494-1570). Aunque defina el derecho como medium rei, sostiene que la explicación de la justicia conmutativa se ve favorecida al emplear la idea de dominium sobre las cosas, porque a partir de él aparecen contratos, convenciones, etc., que forman el contenido de esa vertiente de la justicia ${ }^{11}$. Para Soto, el dominio o propiedad ocupa la posición central del derecho privado; el poder en manos del sujeto y sus diferentes manifestaciones forman la clave para entenderlo. Claro que para marcar con claridad su posición, Soto advierte que

${ }^{9}$ La contribución del los franciscanos al desarrollo de la noción de derecho subjetivo es un asunto discutido. Michel Villey sostuvo que, a causa de su particular espiritualidad, los franciscanos rechazaron las concepciones "realistas" del derecho en favor de concepciones personalistas. Vid, entre otras, M. VILLEY, "La génesis del derecho subjetivo en Guillermo de Ockham" (trad. de R. Le Roy), en Estudios en torno a la noción de derecho subjetivo, Valparaiso, Ediciones Universitarias de Valparaiso, 1976, per totum. En esa línea vid. también el estudio de P. GROSSI, "Usus facti. La nozione di proprietà nella inaugurazione dell'etá nuova", Quaderni Fiorentini per la Storia del Pensiero Giuridico Moderno, 1 (1972), passim. El debate sobre la pobreza evangélica motivado por los franciscanos suele ser considerado el punto de arranque de esas concepciones. Sin embargo, Maximiliane Kriechbaum estima exagerada esa valoración sobre la participación franciscana en el diseño teórico de facultades jurídicas. En el seno de la polémica sobre la pobreza, tanto los franciscanos como sus oponentes utilizaron el mismo vocabulario elaborado previamente por los juristas; además, los franciscanos no pretendieron definir filosóficamente el ius como un poder estrictamente personal, sino destacar que ellos no tenían la capacidad de ejercer acciones judiciales para reivindicar su dominium. Cfr. M. KRIECHBAUM, Actio, ius und dominium in den Rechtslebren des 13. und 14. Jarbunderts, Ebelsbach, Aktiv, 1996, 29 y ss., 55 y ss., 87, entre otras. Annabel S. Brett también matiza el papel desempeñado por los franciscanos (aunque reconoce su relevancia) y dibuja un camino hacia la facultad jurídica más complejo. Vid. A.S. BRETT, Liberty, Right and Nature. Individual Rights in Later Scholastic Thought, Cambridge University Press, 1997, caps. 1-3.

De todas formas, la mentalidad franciscana era particularmente proclive a ver al ser humano como individuo solo ante Dios y desvinculado de las ataduras mundanas, de manera que lo normativo sólo puede emanar de la voluntad divina. El derecho en sentido romanista les resultaba ajeno y de esa nueva mentalidad deriva la consideración del derecho como un juego entre poderes que autorizan y facultades para actuar según las autorizaciones. Sobre el desarrollo de estas ideas en la Baja Edad Media, vid. F. CARPINTERO, "El desarrollo de la facultad individual en la Escolástica", en VV.AA., El derecho subjetivo en su bistoria, cit., 64 y ss.

${ }^{10}$ Vid. A. GUZMÁN, El derecho como facultad en la Neoescolástica española del siglo XVI. Madrid, Iustel, 2009, 30 y ss.

${ }^{11}$ Cfr. D. DE SOTO, De iustitia et iure libri decem. Ed. bilingüe de M. González, Madrid, Instituto de Estudios Políticos, 1967-1968, proemio del lib. IV, 278. 
el ius no se puede identificar con el dominium ${ }^{12}$.

Tanto Vitoria como Soto, pese a su fidelidad al tomismo, muestran una tendencia hacia un entendimiento del orden jurídico-privado como un conjunto de facultades ${ }^{13}$. Pero no afirmaron en ningún caso que esas facultades emanaran desde el mismo individuo; obedecían a causas o razones inducidas desde las necesidades históricas de la comunidad, respetando los principios del derecho natural.

La querencia hacia la consideración del derecho como una facultad es mucho más patente a partir del momento en que el impulso de la Escolástica española es recogido por los jesuitas. Un teólogo perteneciente a esta orden, Luis de Molina (1535-1600), desempeña un papel destacado en esa evolución del concepto de derecho. Dedicó un tratado a las cuestiones jurídicas y lo comenzó, como era habitual, con las acepciones de los vocablos justicia y derecho. De manera inicialmente adherida al tomismo, indica que el ius es el objeto de la justicia, es decir lo justo; esa acepción también puede estar referida al comportamiento adecuado a la ley y desde ahí deriva la acepción de facultad o potestad que tiene un hombre para algo. Observemos que, a diferencia de lo que ocurría en Vitoria y Soto (y por supuesto en Tomás de Aquino), la facultad aparece ya como una acepción de derecho.

La relevancia de esta noción crece enormemente cuando Molina se ocupa de los contenidos de la justicia particular, dividida en conmutativa y distributiva ${ }^{14}$. En efecto, al tratar de los bienes objeto de la justicia conmutativa afirma con rotundidad que entre las distintas acepciones de derecho expuestas anteriormente hay una que resulta particularmente adecuada para esta clase de justicia: la de facultad. Sostiene que entendido de este modo el derecho (ius) no es otra cosa que la facultad de hacer, obtener, exigir o tener algo de cualquier otra manera, cuya contravención sin causa legítima produce injuria al titular de la facultad. El derecho así concebido es medida de la injuria, porque al

\footnotetext{
${ }^{12}$ Cfr. D. DE SOTO, op. cit., lib. IV, q. 1, a. 1, 279. De manera llamativa Soto critica aquí la opinión de Gerson y de Conrado cuando identifican derecho y dominio.

13 Alejandro Guzmán indica que Vitoria sienta las bases para convertir la facultas en la base del derecho privado. Cfr. A. GUZMÁN, El derecho como facultad..., cit., 39-40. Sobre la relación entre el derecho y la propiedad en estos escolásticos, vid. J.J. MEGÍAS, Propiedad y derecho natural en la bistoria. Cádiz, Servicio de Publicaciones de la Universidad de Cádiz, 1994, 120 y ss.

${ }^{14}$ Según las enseñanzas aristotélicas sobre la justicia, que siguen Tomás de Aquino y estos teólogos españoles, esta virtud se despliega en dos vertientes. La primera es la justicia general, que se refiere al cumplimiento de las demás virtudes ordenado por las leyes de la comunidad. La justicia particular (dividida en conmutativa y distributiva) es la justicia en sentido estricto, cuyo objeto es el derecho.
} 
perjudicado sin causa legítima se le hace injuria ${ }^{15}$. Precisa las partes de esta definición aduciendo ejemplos. El derecho del que se habla -explica- es la facultad que, a partir de la naturaleza de la cosa, tiene cada uno a usar sus cosas, comer su alimento, vestir sus vestidos, tomar los frutos de sus árboles, andar por la propia casa o por la vía pública; también están contenidas aquí las facultades que alguien tiene para reclamar lo que ya es suyo o le es debido en virtud de algún contrato, la facultad para continuar en la posesión de las cosas propias, o las que cada uno tiene según la naturaleza de la cosa para recibir gratis algo que otro quiera darle usando de su liberalidad. En todos estos casos, Molina mantiene que el impedimento para el ejercicio de las facultades implica realizar una injuria ${ }^{16}$.

Es interesante comprobar la forma en que Molina utiliza la noción de facultad para estructurar su tratado sobre la justicia. Al ser la acepción de derecho más adecuada para esa tarea, el modelo para llevar a cabo la descripción de las materias propias de la justicia conmutativa es el poder sobre los bienes externos. Efectivamente, Molina explica que los bienes de tipo espiritual como la fama son más dignos y deberían ser estudiados en primer lugar, pero el "orden de la doctrina" dicta que se trate en primer lugar de las facultades ejercidas sobre bienes exteriores, es decir los llamados derechos reales, entre ellos la propiedad privada de forma destacada. Resulta claro que el modelo del derecho privado está constituido por el ejercicio de un poder individual manifestado hacia el exterior.

De todas formas, a partir de las explicaciones ofrecidas, no resulta del todo claro cuales son las instancias desde las que emanan dichas facultades, sobre todo las que dependen de la naturaleza de la cosa. En primer lugar, es preciso tener en cuenta la exigencia de una causa legítima para justificar la intervención en el ámbito de una facultad. Para explicarlo, Molina cita un ejemplo muy difundido desde hacía siglos entre los escolásticos. Se trata de la obligación de devolver la cosa objeto de un contrato de depósito; la obligación procede de la naturaleza misma de la cosa, ya que forma parte de la finalidad misma para la que se constituye el depósito; según la terminología más novedosa de Molina, el depositante tiene un derecho o facultad para reclamar esa devolución. Sin embargo, en ciertos casos el incumplimiento de esa obligación no

\footnotetext{
${ }^{15}$ Cfr. L. DE MOLINA, De iustitia et iure opera ominia. Venecia, 1614, disp. I, cols. 24-25.
}

16 Cfr. ibidem. 
produce injuria, es decir, no daña el derecho; ocurre cuando lo depositado es un arma y su dueño ha enloquecido, porque ante tales circunstancias la obligación consiste en la negativa a devolver lo depositado; no hay injuria, aunque se impida al demente usar su facultad, porque está presente una causa legítima: el temor al mal uso del arma ${ }^{17}$. La causa obedece a motivos y razones diferentes a la manifestación de la mera individualidad; están por así decir mediados por la noción de bien social similar al defendido por la mentalidad romanista.

No obstante, a veces Molina se muestra algo ambiguo al exponer algunas manifestaciones de la naturaleza de la cosa. Cuando menciona el derecho a andar por la calle, por ejemplo, parece indicar que esas facultades no tienen otra justificación que un derecho estrictamente personal; esta impresión se acrecienta si atendemos a una matización de importancia considerable. Según Molina, al hacer algo a lo que se tiene derecho no siempre se ejerce un acto de justicia, aunque su impedimento sin causa legítima sí produzca injusticia. Quien come su alimento, viste sus vestidos o hace algo a lo que tiene derecho usa su derecho, aunque no en el seno de una relación de justicia, porque esta requiere siempre la referencia a otro según la idea aristotélico-tomista ausente en esos ejemplos. Sin embargo, el impedimento de las mencionadas acciones obstaculiza el ejercicio del derecho y, en consecuencia, es injusta ${ }^{18}$. Esta reflexión indica que la naturaleza de la cosa en ocasiones consiste en el respeto a un derecho estrictamente individual que se manifiesta mediante un comportamiento hacia el exterior con independencia de cualquier trabazón interpersonal que confiera el sentido al comportamiento. No hay ningún medium rei que sirva de rasero para inducir lo justo, sino sólo la propia personalidad individual.

La ambigüedad presente en este empleo de la expresión naturaleza de la cosa es inevitable, porque por aquellos años este concepto ya antiguo había adquirido un significado especial. Para Tomás de Aquino la naturaleza de la cosa era una instancia desde la que derivaba derecho natural. A causa del carácter circunstanciado de la mayor parte de los asuntos humanos ese derecho natural no funcionaba al modo de un conjunto de preceptos inmutables e intemporales que debieran servir de modelo rígido para el derecho positivo; al contrario, podía tener a veces un carácter flexible, en la medida en

\footnotetext{
${ }^{17}$ Cfr. ibidem.

${ }_{18}$ Cfr. L. DE MOLINA, op. cit., disp. I, col. 26.
} 
que las exigencias de los asuntos humanos variasen según el rumbo de las circunstancias. A partir de la segunda mitad del siglo XVI, los teólogos escolásticos solidificarán la naturaleza de la cosa. Fue Gabriel Vázquez de Belmonte (1549-1604) quien llevó a cabo esa tarea y Molina siguió ese camino. El sesgo aristotélico-tomista es dejado de lado y entra en su lugar un derecho natural formado por exigencias jurídicas inmutables deducidas rigurosamente desde estructuras metafísicas; a ese orden deberá estar sometido el derecho humano y los comportamientos individuales tendrán en él un asidero férreo para conocer la moralidad de los actos ${ }^{19}$.

Si tenemos en cuenta la doctrina iusnaturalista de Molina, parece claro que las facultades jurídicas estarán claramente delimitadas por las naturalezas metafísicas del orden moral. No obstante, cabe pensar que a veces esas naturalezas protegen precisamente el ejercicio de un comportamiento libre, sin mediación interpersonal. Estas ambigüedades también están presentes en la obra del jesuita Francisco Suárez (15481617), probablemente el integrante más destacado e influyente de la Segunda Escolástica Española.

Resulta particularmente significativo que Suárez escriba un tratado titulado Sobre las leyes y Dios legislador. A diferencia de obras similares que habían escrito otros escolásticos usando la denominación Sobre la justicia y el derecho, Suárez marca los nuevos tiempos otorgando a la ley o norma, el papel fundamental en la realidad jurídica. Y la obra comienza precisamente con las definiciones y etimologías de la palabra ley. Expone diversas nociones que giran alrededor de la noción de regla desde la más general abarcadora de cualquier clase de comportamiento hasta llegar a la más estricta de regla moral: medida de la rectitud de las acciones ${ }^{20}$. Antes de seguir con la explicación de la ley, Suárez indica que esta palabra a veces se usa del mismo modo que el vocablo ius lo que

\footnotetext{
${ }^{19}$ Cfr. por ejemplo, las opiniones de Molina en su De iustitia et iure, cit. Trat. 1, disp. 4, col. 10. Sobre la evolución del derecho natural en la Escolástica, vid. J. HERVADA, Historia de la ciencia del derecho natural. Pamplona, EUNSA, 1987, 215 y ss., especialmente 228 y ss. Vid. también F. CARPINTERO, Justicia y ley natural: Tomás de Aquino y los otros escolásticos, Madrid, Servicio de Publicaciones de la Facultad de Derecho de la Universidad Complutense, 2004, 295 y ss. Carpintero muestra la peculiaridad del planteamiento normativo de Suárez. Por una parte defiende un objetivismo ético extremo, pero por otra describe la realidad jurídica como un juego de poderes que proceden en última instancia de Dios. La naturaleza de la cosa muestra lo bueno, pero la normatividad exige un mandato previo: sin voluntad ordenadora no hay obligación moral ni jurídica. Esa visión de los problemas morales estaba en Escoto. Carpintero nos recuerda que para Tomás de Aquino la obligatoriedad procede más bien de los fines y bienes humanos que reclaman apoyo; es una teoría teleológica de lo normativo.

${ }^{20}$ Cfr. F. SUÁREZ, Tractatus de legibus et deo legislatore. Coimbra, 1612. Ed. bilingüe de J.R, Eguillor, Madrid, Instituto de Estudios Políticos, 1967-1968, Lib. I, cap. 1, 7-10.
} 
justifica la exposición del concepto de derecho.

Comienza con el análisis de las diferentes etimologías de la palabra ius: las palabras iubeo, iustitia y iuxta. Esta última la desdeña inmediatamente y se ocupa con mayor pormenor de las otras dos que marcan los términos del debate acerca del derecho en esa época. Si el derecho procede de iubeo, lo importante es la existencia de un mandato; si se deriva de la justicia, el derecho es lo debido a cada uno.

En efecto, según la etimología procedente de iustitia, el ius es lo conforme a la equidad y a la razón. Esa correspondencia se manifiesta de dos formas. En primer lugar, puede ser lo debido según las virtudes en general; en segundo, lo debido según la justicia y este es el significado más corriente. Citando a Santo Tomás, señala que este es el primer concepto y significado de ius, que no puede identificarse con la ley, ya que el derecho es más bien lo prescrito o medido por la ley. El sabor tomista queda matizado inmediatamente, cuando añade que según la última y estricta significación del derecho (es decir, lo debido según la virtud de la justicia entendida de manera especial) la denominación propia de derecho suele ser la de cierta facultad moral que cada uno tiene sobre algo que es suyo o que se le debe. $\mathrm{Y}$ así, se dice que el dueño de una cosa tiene derecho sobre ella y que el obrero tiene derecho al salario. Suárez relaciona esta idea de facultad no sólo con lo justo tomista, sino también con la definición romana de justicia contenida en el Digesto, dar a cada uno su derecho, porque la facultad moral que cada uno tiene sobre sus cosas es el derecho de cada uno, y reconocerla y otorgarla es el objeto de la justicia ${ }^{21}$.

Según la otra etimología, que deriva de iubere, el derecho significa lo mismo que ley, porque la ley es un mandato o imperativo. Suárez nos indica que este segundo significado propio de la palabra ius es el que seguirá a lo largo del tratado, que, no lo olvidemos, se ocupa de las leyes ${ }^{22}$.

${ }^{21}$ Cfr. F. SUÁREZ, Tractatus de legibus, lib. I, cap. 2, 1-5, 10-11. En otro lugar afirma que la facultad moral es el objeto de la justicia tal y como dice Santo Tomás en la quaestio 57 de la Suma (lo que no es cierto, porque Tomás no menciona ahí la idea de facultad). Y que la ley es la regla de la operación honesta que sirve de razón de la facultad (y cita otra vez el mismo pasaje de Tomás que sí define la ley como la razón del derecho, objeto de la justicia). Suárez añade que la facultad moral a veces aparece como facultad de usar y como ius facti o derecho ejercitado. Cfr. F. SUÁREZ, Defensio fidei catholicae adversus anglicanae sectae errores. Ed. bilingüe de J.R. Eguillor, Madrid, Instituto de Estudios Políticos, 1970, lib. 4, cap. 9, 11, 418. Como señala A. Guzmán, en el pasaje del Tratado sobre las leyes ahora citado, Suárez habla de la facultad como significación propia y estricta del derecho, pero cuando este se toma por lo justo: es decir, lo justo es el respeto a las facultades morales. Cfr. El derecho como facultad, cit., 191.

22 Cfr. F. SUÁREZ, Tractatus de legibus, lib. I, cap. 2, 11, 14. 
La preferencia teórica de Suárez parece clara. Describe la realidad jurídica como un conjunto de leyes y de facultades o posibilidades de actuar conferidas y reguladas por esas leyes. A veces las leyes se encargan de determinar el medium rei en sentido tomista, tal y como ocurre con las reguladoras del precio de las cosas o de las acciones recíprocas ${ }^{23}$. Pero aunque no se olvide de esta idea, resulta claro que para Suárez no forma el núcleo de su teoría.

También está claro que la personalidad estrictamente individual no es fuente exclusiva de juridicidad para la estructura de leyes desplegadas en divinas, naturales y humanas; cada una tiene diferentes causas y razones. Las que dan sentido a la ley natural son interesantes para el problema que ocupa estas páginas.

Su análisis del derecho natural (o de la ley natural, ya que como hemos visto Suárez identifica ley y derecho) es extenso y un tanto alambicado. Entiende que la ley natural está compuesta por preceptos cuya rectitud procede de la naturaleza intrínseca de la cosa, en la línea que había introducido Vázquez de Belmonte y que seguía también Molina. Este tipo de concepciones inquietaba a los teólogos, porque implicaba reconocer principios de moralidad rigurosamente inmodificables que podían limitar la omnipotencia divina. Suárez soluciona el problema indicando que la ley natural lo es porque posee la fuerza otorgada por la voluntad divina. Pero para evitar los excesos voluntaristas añade que Dios quiso crear el mundo con un orden racional, de tal manera que ha de querer prohibir los actos intrínsecamente malos y mandar los intrínsecamente buenos ${ }^{24}$. En cualquier caso, las leyes humanas, que regulan las facultades, deben respetar los preceptos de bondad absoluta contenidos en la ley natural y ordenados por Dios; las causas de las facultades no pueden proceder sólo de la dimensión estrictamente individual ${ }^{25}$. Esa dirección de las facultades jurídicas no sólo proviene de la naturaleza de la cosa, sino también de consideraciones acerca del bien común que han de inspirar al legislador.

No obstante, al igual que ocurre con Molina, cabe preguntarse si Suárez expone alguna facultad que brote directamente de la personalidad individual y lo cierto es que es

\footnotetext{
23 Cfr. F. SUÁREZ, Defensio fidei, lib. 4, cap. 16, 14, 460.

${ }^{24}$ Cfr. Tractatus de legibus, lib. 1, cap. 6, 23, 128.

25 Cfr. F. SUÁREZ, Tractatus de legibus, lib. 3, cap. 12, 4, 241, donde explica que la ley humana sólo puede contener materias "honestas". En sus Disputaciones metafisicas, Suárez mantiene que el bonum honestum es el que es adecuado por sí mismo, con independencia de las consecuencias derivadas de la acción honesta. El honestum es correspondiente a la naturaleza racional, aunque no conlleve utilidad. Además, tiene un carácter a priori. Cfr. Disputaciones metafísicas, disp. 10, sect. 2. (La edición utilizada es la dirigida y digitalizada por S. Castellote, disponible en http://www.salvadorcastellote.com, consultada el 15-05-2011).
} 
perceptible también cierta ambigüedad. Desde este punto de vista, plantea algunas reflexiones interesantes. En una de las ocasiones en que menciona las dos acepciones de la palabra ius (ley y facultad moral) añade que la primera puede ser denominada ius honestum o legale y la segunda ius utile o reale; ambas aparecen en los tres órdenes del derecho, el natural, el de gentes y el civil; el ius utile naturale procede de la misma naturaleza y por ese motivo se dice que la libertad procede del derecho natural ${ }^{26}$. De manera bastante clara, Suárez mantiene que la libertad individual es un derecho natural ${ }^{27}$. Sin embargo, este tipo de facultades (como la libertad natural) pueden verse disminuidas si hay una causa justa (como el bien común) y si esa limitación es realizada por una potestad legítima ${ }^{28}$. Esta matización de los alcances de la libertad puede parecer sorprendente si partimos del carácter inmutable del derecho natural. Pero será entendida fácilmente al tener en cuenta la distinción escolástica entre derecho natural preceptivo y derecho natural permisivo o negativo. El primero ordena y prohibe comportamientos que son buenos y malos en sí mismos; el segundo, en cambio, se limita a dejar abiertas posibilidades de acción diversas sin pronunciarse acerca de su bondad; la libertad natural pertenece al segundo tipo de derecho natural que, a diferencia del preceptivo, es modificable en aras del bien común; en consecuencia, la ley humana positiva no está inexorablemente vinculada a ese derecho natural permisivo ${ }^{29}$. Una argumentación idéntica encontramos cuando Suárez mantiene que hay poderes o actos de dominio privado que no dependen de las leyes humanas ni de la república, sino directamente del mismo derecho natural; pueden ser limitados por el poder político si hay causa justa ${ }^{30}$.

El estudio de los privilegios es otro momento en el que Suárez identifica las facultades jurídicas con las libertades. El privilegium aparece denominado como derecho (ius), facultad moral, potestad, inmunidad y libertad; de acuerdo con esta última

\footnotetext{
${ }^{26}$ Cfr. F. SUÁREZ, Tractatus de legibus, lib. 2, cap. 17, 7, 180.

${ }^{27}$ Para la mentalidad romanista la libertad era de derecho natural, pero no aparecía configurada como un derecho en el sentido de una facultad personal.

${ }^{28}$ Cfr. F. SUÁREZ, Tractatus de legibus, lib. 3, cap. 30, 10, 371. Lo mismo escribe en Defensio fidei, lib. 4, cap. 9, 11, 418. (Esta cita se refiere a la postestad eclesiástica, pero el argumento es aplicable también al poder político).

29 Cfr. F. SUÁREZ, Tractatus de legibus, lib. 2, cap. 14, 6-18, 156 y ss. Sobre los efectos de esta consideración del derecho natural a la hora de introducir regulaciones contrarias a la libertad y comunidad de bienes originarias vid. J.J. MEGÍAS, Propiedad y derecho natural..., cit., 259 y ss.

El derecho natural permisivo es el trasunto sofisticado y escolástico del estado de naturaleza romanista: una situación de libertad originaria que se ve sustituida en función de la utilidad común (derecho de gentes) o propia de una comunidad política (civil).

${ }^{30}$ Cfr. F. SUÁREZ, Tractatus de legibus, lib. 5, cap. 31, 15, 608.
} 
denominación el privilegio implica ausencia de obligatoriedad y de sometimiento ${ }^{31}$. Las inmunidades contenidas en los tratados suarecianos obedecen a causas y utilidades diversas y no son derechos destinados a proteger una esfera de individualidad privada, tal y como ocurre con los actuales derechos fundamentales. Por lo demás, no es exagerado afirmar que el tratamiento de estas inmunidades por parte de Suárez es bastante similar al que efectúa la ciencia jurídica actual de los llamados derechos subjetivos. Los privilegios concedidos a uno exigen de los demás la obligación de abstención: todo derecho concesivo requiere de un derecho preceptivo ${ }^{32}$. Suárez explica que el grado de libertad del que goza el titular del derecho no siempre es el mismo. Diferencia los privilegios de derecho privado (iura privata) de los propios del derecho público. Los primeros son permisos o dispensas que pueden ser aprovechados o no; en cambio, los privilegios de derecho público -como los concedidos a los eclesiásticos- tienen “fuerza de precepto" y, en consecuencia, son irrenunciables. Ese carácter se debe a la justificación de su concesión: en el caso de la inmunidad eclesiástica su razón es de derecho divino y por tanto indisponible ${ }^{33}$. Conviene advertir que no todas las facultades jurídicas ejercidas en virtud de leyes son conceptuadas como privilegios, tan sólo las que proceden de leyes especiales concedidas por algún motivo y que se distinguen de las normas de derecho común. De todas formas es interesante comprobar la extensión del tratamiento que dedica Suárez a los privilegios: un libro entero de su Tratado sobre las leyes.

\section{Libertad, derecho y poder político}

Los escolásticos españoles dedicaron especial atención a la libertad al tratar el origen del poder político. Estos autores estaban de acuerdo en que todos los hombres son por naturaleza libres e iguales y en que el poder político reside de forma inmediata en la comunidad (respublica), aunque de manera mediata (como todo lo existente) proceda de Dios. Aunaban de esta forma dos ideas ya tradicionales: el estado de naturaleza romanista y el origen comunitario del poder político, que había sido difundido en Europa desde el siglo XIII gracias al redescubrimiento de las obras políticas de Aristóteles ${ }^{34}$.

\footnotetext{
${ }_{31}$ Cfr. F. SUÁREZ, Defensio fidei, lib. 4, cap. 1, 5, 374-375, cap. 9, 11, 418, cap. 14, 1, 445, cap. 30, 20, 530.

32 Cfr. F. SUÁREZ, Tractatus de legibus, lib. 2, cap. 17, 7, 186.

${ }^{33}$ Cfr. F. SUÁREZ, Defensio fidei, lib. 4, cap. 30, 20, 530-531.

34 Sobre la difusión de esa noción aristotélica del origen del poder, vid. W. ULLMANN, Historia del
} 
Es llamativo que esa defensa de la libertad individual no aparezca al estudiar el concepto de derecho, sino la justificación del poder político. En este punto los escolásticos tienen bastante clara la defensa de un origen democrático del poder. Juan Roa Dávila (1552- ca.1630) repite una y otra vez que el consentimiento del pueblo es el fundamento del poder, porque Dios hizo al hombre libre ${ }^{35}$. Matiza inmediatamente señalando que gracias a esa libertad es posible elegir al gobernante, lo que es muy necesario y acorde con el derecho natural, porque los ciudadanos particulares no siempre actúan de acuerdo con la recta razón y necesitan alguien que los dirija ${ }^{36}$. Pero este "paternalismo" desaparece cuando explica que la cesión del poder político no es absoluta, gracias al expediente del contrato. Efectivamente, a causa de la libertad natural de los hombres, el poder de uno sobre otro sólo está justificado por el sometimiento espontáneo; en consecuencia, todo lo referente al poder político debe estar regulado según el consenso y la costumbre de la comunidad. La razón natural prescribe el cumplimiento de promesas y pactos y ese precepto obliga también a los gobernantes. Ahora bien, en el contrato que constituyó el poder la utilidad pública y la religión quedaron a salvo, y si el gobernante lesiona ambos principios la comunidad puede quitarle el poder. En ningún caso puede entenderse que la comunidad renuncia a su derecho (ius) de procurar la utilidad común: el origen del poder obedece sólo a conseguir el mayor bien para la comunidad y ha sido realizado de manera libre ${ }^{37}$.

La importancia concedida en la España de aquellos años a la libertad y al consentimiento en el surgimiento del poder, alcanzó manifestaciones aun más radicales que las escolásticas. El jurista Fernando Vázquez de Menchaca aceptó los retos que lanzaba el estado de naturaleza romanista y defendió con claridad que el pacto es la única fuente de la vida social y política, ya que todos somos libre por naturaleza y cualquier clase de sometimiento es un mal. Vázquez ya no escribe sobre la utilidad de la república, sino

\footnotetext{
pensamiento politico medieval (trad.. R. Vilaró), Barcelona, Ariel, 1983, 153 y ss.

${ }^{35}$ Cfr. J. ROA DÁVILA, De regnorum iustitia (ed. bilingüe de L. Pereña), Madrid, CSIC, 1970, 1, 1, 3 y ss. El pacto o contrato social como origen del poder político era ya entonces una idea difundida, especialmente entre los autores españoles. Sobre el discurrir de esta teoría desde sus antecedentes antiguos y medievales vid. J. GOUGH, The Social Contract, Oxford, Clarendon Press, 1957.

${ }^{36}$ Cfr. J. ROA DÁVILA, De regnorum iustitia, 1, 2, 8.

${ }^{37}$ Cfr. J. ROA DÁVILA, De regnorum iustitia, 1,2,1, 10 y 1,2,2, 11. Esta obra de Roa Dávila fue prohibida, pero esa prohibición resulta significativa: procedió de la Inquisición romana debido a las limitaciones que el autor establecía a la potestad eclesiástica. En cambio, la monarquía española intercedió sin éxito por él, y eso indica que esta teoría del poder político era aceptada de buen grado en España.
} 
de la utilidad de los ciudadanos (utilitas civium); su protección es la única finalidad de un gobierno justo ${ }^{38}$.

Luis de Molina sigue estos carriles de manera más moderada al escribir sobre la potestad política, y sin hacer tanto hincapié en el consenso. Sostiene que la potestas se divide en dos: natural y civil; la primera, emanada directamente del derecho natural, es la que poseen los padres sobre los hijos; la segunda surge de la voluntad de los hombres (es decir, del consentimiento) $)^{39}$.

Francisco Suárez también defiende la posición originaria de la libertad, porque explica que el hombre es libre por naturaleza y no está sometido a nadie excepto a su creador $^{40}$. Sin embargo, esta realidad natural no supone que el poder político y la legislación consiguiente sean contrarios a la naturaleza. Y es que el hombre también es propenso a la sociedad política a causa de la necesidad de coordinar las acciones. Al igual que el cuerpo necesita una cabeza, la sociedad requiere un poder supremo ${ }^{41}$. Suárez se apoya en Aristóteles, pero también en la procedencia divina de la tendencia natural a la vida social. Esta dualidad puede oscurecer la cuestión de la titularidad del poder político. En última instancia está en Dios, pero de manera inmediata en los hombres. Esta afirmación debe entenderse cuidadosamente.

En primer lugar es preciso decir que el poder surge de la propia naturaleza de la cosa, es decir, que pertenece al derecho natural prescriptivo y por tanto está dotado de la inmutabilidad propia de ese orden jurídico. No reside en ningún hombre individualizadamente, ni en una mera agregación accidental de hombres, sino en la comunidad unida en un sentido moral que forma un cuerpo místico. Esta expresión aplicada a la política era popular y antigua entre estos pensadores; indicaba que la comunidad era una persona "ficta", es decir una persona jurídica dotada de entidad propia y situada más allá de la simple suma de particularidades ${ }^{42}$. El poder pertenece al pueblo en

38 Cfr. F. VÁZQUEZ DE MENCHACA, Controversiarum Illustrium Aliarumque usu frequentium libri tres, Venecia, 1574, lib. 1, cap. 1, 9-10, 17, entre muchas otras. Debemos a Francisco Carpintero el haber mostrado el cariz moderno e individualista de estas ideas de Vázquez de Menchaca, que muestran el paso a la Modernidad iusnaturalista. Vid. F. CARPINTERO, Del Derecho Natural Medieval al Derecho Natural Moderno: Fernando Vázquez de Menchaca. Salamanca, Servicio de Publicaciones de la Universidad de Salamanca, 1977, per totum, y los estudios citados en la nota 1.

${ }^{39}$ Cfr. L DE MOLINA, De iustitia, cit., t. 2, disp. 20, 93.

${ }^{40}$ Cfr. F. SUÁREZ, Tractatus de legibus, lib, 3, cap. 1, 1, 197.

${ }^{41}$ Cfr. F. SUÁREZ, Defensio fidei, lib. 2, cap. 1, 4-5, 215.

42 Sobre el origen del uso político de la expresión cuerpo místico, vid. E.H. KANTOROWICZ, The King's Two Bodies, Princeton University Press, 1957, 194 y ss. Por otra parte, la mención que hace Suárez de la 
su conjunto concebido como un todo perfecto o cuerpo de la comunidad, porque es requisito necesario para su conservación ${ }^{43}$. Estas afirmaciones parecen indicar que existe una diferencia ontológica entre el ámbito individual y el político, ya que este posee una entidad propia en razón de la conservación de la comunidad, pero la idea de persona "ficta" nos indica que concibe a la sociedad política constituida como una persona artificial. Tampoco menosprecia el papel del individuo en el surgimiento del poder político cuando afirma que la forma política natural es la democracia, basada en la igual libertad de todos. Sin embargo, esta democracia (al igual que la libertad natural) pertenece al plano del derecho natural permisivo: no es una exigencia inmutable de justicia que el poder haya de permanecer siempre democrático. Consecuentemente, la libertad puede ser limitada, aunque para ello, advierte Suárez, es preciso un título legítimo ${ }^{44}$. Si al explicar el derecho esas causas legítimas eran diversas, al justificar el origen de un régimen político concreto Suárez enumera tres: acuerdo voluntario, guerra justa o costumbre ${ }^{45}$. En otro momento precisa que el principado regio sólo está fundamentado en un pacto de la sociedad humana, en un consenso eficaz y voluntario del todo el pueblo, ya sea explícito o implícito ${ }^{46}$.

En realidad, la base democrática está siempre presente, aunque se opte por una monarquía. El fundamento consensual establece los límites para el poder político del rey: si se transforma en tirano, el pueblo podrá hacer uso de su "potestad natural de autodefensa" de la que nunca se desprendió ${ }^{47}$. El rey tiene el poder supremo, pero sólo en la medida en que se lo ha concedido el pueblo; no puede ejercerla arbitrariamente ni en su propio beneficio, sino en función del bien común de los que le han conferido ese poder ${ }^{48}$. Suárez se refiere expresamente a la utilidad de "aquellos" (eorum) que cedieron el poder al príncipe; de esa forma, parece identificar la utilidad y el bien común con el bien particular de cada uno de los integrantes del pueblo, aunque inmediatamente matice y distinga entre

comunidad moral no ha de ser entendida en un sentido parecido al comunitarismo moral de la actualidad, sino como capacidad de actuación moralmente relevante, es decir, de actuación práctica y no meramente física o mecánica.

43 Cfr. F. SUÁREZ, Defensio fidei, lib. 3, cap. 2, 5-7, 218-219.

44 Cfr. F. SUÁREZ, Defensio fidei, lib. 3, cap. 2, 8-9, 220.

45 Cfr. F. SUÁREZ, Tractatus de legibus, lib. 5, cap. 17, 5, 544.

${ }^{46}$ Cfr. F. SUÁREZ, Defensio fidei, lib. 2, cap. 3, 11, 221, lib. 3, cap. 2, 11,

${ }^{47}$ Cfr. F. SUÁREZ, Defensio fidei, lib. 3, cap. 3, 3, 225.

${ }^{48}$ Cfr. F. SUAREZ, Defensio fidei, lib. 3, cap. 7, 5, 253, lib. 4, cap. 3, 12, 386. Tractatus de legibus, lib. 1, cap. $7,5,40$. 
la utilidad privada y la común, que no han de coincidir siempre ${ }^{49}$.

Esta exposición sobre el poder resulta interesante para el concepto de derecho. Tal y como indicaba párrafos atrás, estas doctrinas democráticas sustentan el origen del poder, no del derecho. Por tanto, sus causas podrán ser al menos parcialmente diferentes. Durante la Edad Media aparecía bastante clara la diferencia entre el derecho y la política; los gobernantes no tenían como misión crear derecho, sino -entre otras cosas- proteger un orden jurídico creado desde instancias sociales múltiples ${ }^{50}$. La mentalidad romanista, con su diferencia entre ius y lex, formaba parte de esta corriente ${ }^{51}$. La época de Molina y Suárez asiste al ascenso del poder de las monarquías territoriales y a su pretensión de controlar la producción del derecho; no consiguieron ese monopolio por la inercia social y la resistencia de los órdenes existentes, estamentos, etc., pero desde luego la intención existió $^{52}$. El problema está reflejado de manera intensa aunque oblicua en la obra de Suárez.

En efecto, como hemos visto, él identifica prioritariamente el derecho con la ley y la ley a su vez es expresión del poder político; en consecuencia, los orígenes del derecho y del poder inevitablemente se solaparán ${ }^{53}$. Si el poder pertenece originariamente a la comunidad y se basa en la igual libertad de los hombres, el derecho-ley también habrá de tener ese fundamento. Suárez no llega a explícitamente a esa conclusión, porque trata separadamente esas cuestiones.

\footnotetext{
${ }^{49}$ Cfr. F. SUÁREZ, Tractatus de legibus, lib. 1, cap. 7, 14, 42. Suárez no piensa que la sociedad política sea una entidad que absorba y diluya a los individuos. Un ejemplo lo encontramos cuando mantiene que un súbdito no tiene obligación de pagar un tributo cuando, tras un "juicio probable" (no es posible pedir certeza absoluta en los asuntos humanos), llega a la conclusión de que dicho tributo es injusto. Cfr. Tractatus de legibus, lib. 5, cap. 18, 19, 551.

${ }^{50}$ Cfr. P. GROSSI, L'ordine giuridico medievale, Roma-Bari, Laterza, 1996, 40 y ss.

${ }^{51} \mathrm{Al}$ mismo tiempo los romanistas tendían a considerar al príncipe como fuente originaria del derecho. Vid. KANTOROWICZ, The King's Two Bodies, cit., 97 y ss. Y tengamos en cuenta que la distinción romana clásica entre auctoritas y potestas estaba transmitida por la Compilación de Justiniano que era, en conjunto, una obra legislativa a pesar de resumir en el Digesto el derecho creado por los juristas romanos.

52 Vid. H. MOHNHAUPT, "Potestas legislatoria und Gesetzesbegriff im Ancien Régime", Ius Commune, 4 (1972), per totum.

${ }^{53}$ La ley es, según Suárez, un acto de jurisdicción (iurisdictio). Y la iurisdictio es una forma de dominium es decir, de poder. Cfr. Tractatus de legibus, lib. 1, cap. 5, 15, 28, lib. 3, cap. 1, 7, 199, lib. 4, cap. 1, 7, 364, donde explica que la jurisdicción y el dominio no consisten en cualidades físicas, sino en un derecho y potestad moral. Suárez (y también Molina) siguen aquí el modelo de Diego de Covarrubias, que escribió que la jurisdicción era una forma de dominio, como el poder de los particulares sobre sus bienes, aunque en el primer caso lo ejerciera el poder político. Cfr. Regulae Peccatum, de regulis iuris, libro sexto relectio $\ 9$, 8, en Opera Omnia, Amberes, 1615, 505. Desde la Edad Media, el término dominium nombraba una pluralidad de poderes jurídicos, además de lo que hoy denominamos propiedad privada. Vid. D. WILLOWEIT, "Dominium und proprietas. Zur Entwicklung des Eigentumsbegriffs in der mittelarterlichen und neuzeitlichen Rechtswissenschaft", Historisches Jahrbuch der Görres-Gesellschaft, 1974, 136.
} 
Recordemos que para Suárez (y para todos los escolásticos) la ley debe ser justa y proceder de la voluntad política legitimada para legislar. El asunto está claro aparentemente, pero Suárez lo complica al estudiar el papel de esa voluntad en la creación de la ley. Explica que la ratio legis (el fin y justificación de la ley) es una medida externa o extrínseca de la ley. Ocurre que el acto moral, del que la legislación es un ejemplo, no se constituye formalmente desde el motivo de la operación, sino desde la voluntad libre; la razón intrínseca y constitutiva de la ley, su esencia y forma, es precisamente esa voluntad. La adecuación a la materia honesta es necesaria, porque proporciona la razón objetiva de la ley, pero no es su constituyente formal, que parece ser lo verdaderamente importante para Suárez ${ }^{54}$. Es cierto que al negar condición de ley al mandato injusto, acepta que respetar la ley natural es condición necesaria para la juridicidad, pero el lector obtiene la impresión de que la voluntad ordenadora es el elemento verdaderamente identificador de la legislación. Esa voluntad es ejercicio de la potestad política, y debemos recordar que el poder se fundamenta en el consenso de la comunidad originaria de hombres libres e iguales que transmiten su poder al gobernante. Si la ley es la acepción principal del derecho, tendremos que reconocer que el origen del derecho estará en la libertad natural. De todas formas, Suárez no lleva a cabo este encadenamiento de ideas.

La mención a la voluntad libre como elemento formal de la ley requiere alguna atención. En las Disputaciones metafísicas se ocupa de la diferencia entre el bonum naturale y el bonum morale. Tras ofrecer la explicación metafísica sobre la teleología ínsita en las naturalezas y que permite identificar lo bueno con lo natural, Suárez nos informa de otra manera de plantear la cuestión según el tipo de operación; la natural es la que brota necesariamente de la fuerza (impetus) de la cosa, y la operación moral es la libre y racional ${ }^{55}$. Claro que no hay que exagerar esa identificación de la moral con la libertad: el bonestum no procede de una autorregulación de la propia libertad, sino que preexiste a la razón: una conducta no es buena y honesta porque la recta razón la enjuicie como tal, sino viceversa ${ }^{56}$. El hombre es libre, sostiene Suárez, y no está sometido a nadie excepto a su creador que, recordemos, también lo es del derecho natural.

\footnotetext{
${ }^{54}$ Cfr. F. SUÁREZ, Tractatus de legibus, lib. 3, cap. 20, 10-17, 285 y lib. 3, cap. 26, 8, 308.

${ }^{55}$ Cfr. F. SUÁREZ, Disputationes metaphysicae, cit., disp. 10, sect. 30.

${ }_{56}$ Cfr. F. SUÁREZ, Disputationes metaphysicae, cit., disp. 10, sect. 2. Y como buen escolástico, Suárez no olvida que sólo Dios es bueno en sí mismo (simpliciter), porque las criaturas sólo pueden serlo secundum quid o por participación.
} 
Suárez no podía llevar a sus últimas consecuencias una concepción del derecho basada en el poder, porque la ley natural y los contenidos objetivos pesan decisivamente a la hora de configurar el derecho. El derecho es un poder, pero delimitado por la naturaleza de la cosa y el bien común; esta tesis fue compartida por todos estos escolásticos y de ahí que no expusieran una visión abiertamente individualista del derecho ${ }^{57}$. Tal y como decía páginas atrás, no es lo mismo diseñar una concepción de la facultad jurídica, que identificar la facultad con la libertad individual. Los escolásticos como Suárez avanzaron mucho en la primera vía, pero no llegaron a la segunda.

Desde luego, caben pocas dudas de que elaboraron un concepto bastante acabado de facultad que tendrá éxito en los ordenamientos privados posteriores. Suárez, a partir de las especulaciones medievales, entendió la realidad jurídica como un entramado de poderes autorizadores y sujetos dotados de facultades; aunque las razones de las autorizaciones brotaran de demandas morales objetivas, esa manera de ver el asunto era ya incipientemente moderna. $Y$ al final, atisbaron que algunas de esas facultades estaban adheridas a la existencia estrictamente individual. Sin ellos difícilmente habría brotado el concepto moderno de derecho como libertad personal ${ }^{58}$.

\section{Conclusión}

Al comenzar mencionaba el papel de puente hacia los planteamientos iusnaturalistas modernos desempeñado por Hugo Grocio. Desde luego, este no fue un revolucionario. Influido por escolásticos y juristas españoles adoptó tanto la concepción intelectualista del derecho natural (sin las sutilezas de Suárez) como la identificación del derecho con una "cualidad moral"; a partir de ese poder se estructura el orden jurídico, construido

\footnotetext{
57 Vid. al respecto, J.J. MEGÍAS, "De la facultad moral a la cualidad moral: El derecho subjetivo en la Segunda Escolástica tardía”, Anuario de Filosofía del Derecho, 9 (1992), per totum. La misma opinión sobre la doctrina jurídica de Suárez en R. MACIÁ, Doctrinas modernas iusfilosóficas, Madrid, Tecnos, 1996, primera parte, 27 y ss. Avelino Folgado rechazaba las descripciones modernizadoras de Suárez, porque en este teólogo existe una base objetiva clara para el derecho y, en consecuencia, para las facultades: la norma debe ser conforme con el orden que la razón descubre; por eso sus diferencias con Vitoria y Soto son de matiz: sustituye iustum por facultas. Cfr. A. FOLGADO, Evolución histórica del concepto de derecho subjetivo, San Lorenzo del Escorial, Pax Juris, 1960, 51 y ss. Folgado exagera la falta de novedad de Suárez.

58 Sobre los indicios de moldes individualistas para las facultades jurídicas en Molina y Suárez, vid. F. CARPINTERO, "El desarrollo de la idea de libertad personal en la Escolástica", cit., 214 y ss. Vid. F. CARPINTERO, "Los escolásticos españoles en los inicios del liberalismo político y jurídico", en Revista de Estudios Histórico-Jurídicos, 25 (2003), per totum. Sobre el engarce con los modernos mediante el desarrollo del concepto de facultad, cfr. A. GUZMÁN, El derecho como facultad..., cit., 257.
} 
mediante promesas y pactos realizados por individuos ${ }^{59}$. De esa forma contradictoria enlazaba las dos vías propuestas por los autores españoles entre los siglos XVI y XVII.

El afianzamiento del subjetivismo jurídico llegará poco después de las manos de la triunfante Escuela de Derecho Natural Moderno. Su iniciador formal, Samuel Pufendorf (1632-1694), definió el derecho (ius) como "cualidad moral activa" expandida a modo de espacio de libertad; unió a esta noción la de estado de naturaleza, de manera que el derecho natural era la libertad propia del estado de naturaleza ${ }^{60}$. La diferencia, fundamental, con los escolásticos reside en el modo de limitar esa libertad. Siguiendo la línea de Vázquez de Menchaca, Pufendorf mantiene que el consentimiento del individuo es el único medio legítimo de crear normas; sólo la autolimitación de la libertad está justificada para crear un orden político y jurídico. Ampliando el modelo de Grocio, el derecho según Pufendorf es un edificio sistemático elaborado a partir de la libertad o poder natural mediante sucesivos acuerdos entre individuos. A pesar de esas diferencias, está claro que ese concepto de derecho no habría sido posible sin el trabajo previo de los escolásticos ${ }^{61}$.

Aunque estos modernos sigan recurriendo a la ley natural, su papel será diferente. La naturaleza objetiva de la cosa, que daba el sentido a la ley natural escolástica, ha desaparecido. Las tendencias más individualistas de la época no podían aceptar esas instancias moralizadoras surgidas más allá de la esfera puramente individual ${ }^{62}$. A partir de

\footnotetext{
${ }^{59}$ Sobre su concepto de derecho cfr. H. GROCIO, De Jure Belli ac Pacis libri tres, Amsterdam, 1651, lib. 1, cap. $1,4,2$.

${ }^{60}$ Cfr. S. PUFENDORF, De Iure Naturae et Gentium libri octo, Frankfurt / Leipzig, 1759, lib. 1, cap. 1, 20, 20.

${ }^{61}$ Pufendorf divide la realidad en entes físicos (dominados por la necesariedad mecánica) y entes morales (producto de la acción de seres libres); el derecho, como cualidad moral, y la ley forman parte de los entia moralia. Cfr. De Iure Naturae..., cit., lib. 1, cap. 1, 2, 5 y ss. Esa distinción ya la encontramos en Suárez, aunque Pufendorf no cite al escolástico. Es llamativo que aporte una explicación sobre el voluntarismo divino parecida a la de Suárez; Dios es absolutamente libre, pero una vez que decidió crear un mundo en el que existiera la sociabilidad natural del hombre (en un sentido individualista), no pudo sino establecer la ley natural existente. Cfr. S. PUFENDORF, De Jure Naturae ..., cit., lib. 2, cap. 3, 14, 180.

${ }_{62}$ Este fue un problema considerable para el iusnaturalismo moderno, porque afectaba al fundamento mismo del pacto originario. Pufendorf se mostró ambiguo. En un lugar de su obra explicó que la ley natural nos muestra lo honesto en sí mismo. Cfr. S. PUFENDORF, De officiis hominis et civis prout ipsi praescribuntur lege naturali libri duo. Giessae, 1731, prefacio, 1. En otro momento explicó que la ley natural tenía como fin principal impeler al pacto en función de la utilidad individual, aunque no lo expresara así. Cfr. De Jure Naturae ..., cit., lib. 2, cap. 1, 8, 148-149, lib. 2, cap. 3, 160 y ss. Sobre todo, $\ 13$ y ss., 196 y ss.

Era la línea marcada, con más radicalidad, por Hobbes cuando explicaba que las leyes naturales, que prescribían salir del estado de naturaleza mediante un pacto, eran meras reglas técnicas sin valor moral; tendrán ese valor si las consideramos mandatos divinos. Cfr. T. HOBBES, Leviathan, en The English Works of Thomas Hobbes. Ed. de W. Molesworth, 1839, Aalen, reprint de Scientia, 1966, I, cap. 15, 147; II,
} 
ahora el nuevo derecho natural será un procedimiento encargado de construir el Estado a partir del consentimiento entre individuos libres. Desde este punto de vista, el derecho no podrá ser otra cosa que el conjunto de leyes emanadas del Estado nacido a su vez del pacto. Los escolásticos, como Suárez, a pesar de la importancia que otorgaron a las facultades dentro del orden jurídico y a su defensa de la libertad, no habrían aceptado ese rechazo de las naturalezas metafísicas que cimentaban, desde su punto de vista, la vida moral de la sociedad.

cap. 31,348 . 